\title{
O MUNDO E O REINO: HISTORICIDADE E FICCIONALIZAÇÃO EM EL REINO DE ESTE MUNDO, DE ALEJO CARPENTIER
}

\author{
THE WORLD AND THE KINGDOM: HISTORICITY AND FICTIONALIZATION IN \\ ALEJO CARPENTIER'S NOVEL THE KINGDOM OF THIS WORLD
}

Fábio Aristimunho Vargas ${ }^{1}$ Universidade Estadual do Oeste do Paraná (Unioste), Foz do Iguaçu-PR, Brasil

\begin{abstract}
Resumo: O romance El reino de este mundo (1949), do escritor cubano Alejo Carpentier (1904-1980), é uma obra de ficção histórica que retrata a colônia francesa de Saint-Domingue no século XVIII até as primeiras décadas do Haiti independente, introduzindo o estilo narrativo conhecido como "real maravilhoso", que muito influenciaria a literatura latino-americana do século XX. Embora a narrativa não mencione datas nem nomeie fatos, é possível reconhecer e datar os principais acontecimentos retratados, assim como identificar certos personagens reais que aparecem na trama. O presente artigo busca desvendar os elementos históricos referidos e ficcionalizados por Carpentier ao longo da obra, buscando separar o mundo (real) do reino (da ficção), de modo a fornecer subsídios para melhor compreensão da narrativa. Analisam-se, para isso, as quatro partes em que se estrutura o livro, contrastando a narrativa com fatos históricos e elementos da teoria da ficção histórica.
\end{abstract}

Palavras-chave: Ficção histórica; descolonização; pós-colonialidade.

Abstract: The novel El mundo de este mundo (1949), by Cuban writer Alejo Carpentier (1904-1980), is a work of historical fiction that portrays the French colony of SaintDomingue in the XVIII century until the first decades of independent Haiti, introducing the style of narrative known as "marvelous real", which would greatly influence the XX century's Latin American literature. Although the narrative does not mention dates or facts, it is possible to recognize and date the main events portrayed, as well as to identify certain real characters that appear in the plot. The present article seeks to uncover the historical elements referred to and fictionalized by Carpentier throughout his work, seeking to separate the (real) world of the realm (of fiction), in order to provide subsidies for a better understanding of the narrative. For this, this article analyzes the four parts of the book, contrasting the narrative with historical facts and elements of the theory of historical fiction.

Keywords: Historical fiction; decolonization; postcoloniality.

\footnotetext{
${ }^{1}$ Doutor em Integração da América Latina pelo PROLAM/USP e mestre em Direito Internacional pela USP. Contato:<fabioaristimunho@gmail.com>.
} 


\section{INTRODUÇÃO}

A Revolução Haitiana, retratada pela tensão entre colonos brancos e negros escravos na convulsionada colônia francesa de Santo Domingo, assim como as contradições do Haiti independente, é o pano de fundo do romance El reino de este mundo (1949), do escritor cubano Alejo Carpentier (1904-1980), publicado como $O$ reino deste mundo na edição brasileira (Martins Fontes, 2009)

Essa obra é especialmente reconhecida por ter introduzido o Real Maravilhoso, estilo narrativo que muito influenciaria a literatura latino-americana do século XX. Em seu Prólogo ao livro, Carpentier tece um comparativo entre a pretensão europeia de caracterizar o maravilhoso, em especial o surrealismo, e o maravilhoso encontrado nas terras haitianas. O Real Maravilhoso de Carpentier considera fantástica a própria natureza do Continente, interpreta a presença do maravilhoso como um patrimônio da região. Esse Prólogo costuma ser mais referido do que a obra em si, cuja narrativa fica muitas vezes em segundo plano; neste artigo, o enredo é que será objeto de análise.

Sob diversos aspectos, $O$ reino deste mundo pode ser enquadrado na categoria “ficção histórica". Trata-se de uma ficcionalização do passado histórico, em que há um cruzamento entre o plano individual (a vida do personagem Ti Noel) e o plano coletivo (a Revolução Haitiana e o papel específico dos personagens históricos representados na obra, cobrindo o período de entre a segunda metade do século XVIII e as primeiras décadas do XIX). Observa-se uma perfeita concatenação entre os acontecimentos históricos e os rumos da narrativa, numa relação de mútua influência. Por essa perspectiva, El reino de este mundo filia-se à melhor tradição do romance histórico, representada por obras como Ivanhoé (1819), de Walter Scott, Guerra e paz (18651869), de Léon Tolstói, Memórias de Adriano (1951), de Marguerite Yourcenar, e Memorial do convento (1982), de José Saramago, mas também inaugura um subgênero literário que viria a ser denominado "a nova novela histórica da América Latina", conforme se verá.

A narrativa em questão não menciona datas nem nomeia fatos, embora especifique a passagem do tempo: "Quatro anos durou a espera"; "Transcorreram vinte anos depois disso tudo" (CARPENTIER, 2009, p. 37 e 50). No entanto, é possível reconhecer e datar os principais acontecimentos retratados, assim como identificar 
certos personagens reais que aparecem na trama. $\mathrm{O}$ autor adverte, em seu Prólogo, que o relato da obra teria sido estabelecido sobre "uma documentação extremamente rigorosa", que não somente respeitaria "a verdade histórica dos acontecimentos, de nomes de personagens - inclusive secundários -, de lugares e até de ruas, mas também oculta, sob sua aparente intemporalidade, um minucioso cotejo de datas e de cronologias". (CARPENTIER, 2009, p. 11)

Observa-se, assim, certa tensão entre o "mundo" e o "reino" em El reino de este mundo: o mundo real e o reino da ficção, em uma dialética baseada no cruzamento de dois campos discursivos. A convergência entre narrativa histórica e narrativa ficcional dá origem à chamada narrativa de ficção histórica. ${ }^{2}$

O presente artigo tem por objetivo desvendar os elementos históricos referidos e ficcionalizados por Carpentier ao longo de El reino de este mundo, buscando separar o mundo (real) do reino (da ficção), de modo a fornecer subsídios para melhor compreensão da narrativa. A obra é estruturada em quatro partes, as quais são resumidas e analisadas nos itens a seguir.

\section{A REVOLTA DE MACKANDAL}

$\mathrm{Na}$ história narrada por El reino de este mundo, a primeira parte está centrada na revolta liderada por Mackandal na década de 1750. François Mackandal (?-1758), originário da África, era o "filho de um chefe islamizado da Guiné"3 que liderou uma revolta de escravos, sendo considerado um "Houngan", ou Supremo Sacerdote, pela religião vodu haitiana. ${ }^{4}$ A revolta em si é retratada, no livro, em detalhes cruentos.

Segundo a narrativa da primeira parte do livro, toda a planície norte teria sido invadida por um estranho e desconhecido veneno, que matava vacas, bois, novilhos, cavalos, ovelhas, infestando toda a comarca com um interminável fedor de carniça. As fogueiras não davam conta da demanda e os animais continuavam desabando. Os

\footnotetext{
${ }^{2}$ Segundo Marilene Weinhardt, não interessa à ficção histórica repetir "o relato dos acontecimentos magnos, mas ressuscitar poeticamente os seres humanos que viveram tal experiência. Essa forma literária deveria fazer com que o leitor apreendesse as razões sociais e individuais que fizeram com que os homens vivendo aquele tempo e habitando aquele espaço pensassem, sentissem e agissem da forma como o fizeram". (WEINHARDT, 2011, p. 27)

${ }^{3}$ Enciclopédia Mirados Internacional, 1976, v. 11, p. 5639.

${ }^{4} \mathrm{O}$ vodu haitiano é uma religião baseada no culto aos loas (espíritos), originária de povos da África Ocidental, sobretudo no Daomé, possuindo ainda elementos cristãos e indígenas.
} 
telhados viviam repletos de aves carniceiras e as moscas verdes a tudo infestavam. Para surpresa de todos, o veneno começou a se espalhar também pelas casas, fulminando sem aviso os proprietários. Havia um grande temor pelo veneno de origem desconhecida e a todo momento havia enterros. Temerosos e à procura de uma explicação, os colonos açoitavam e torturavam seus escravos, enquanto o veneno continuava dizimando famílias, levando consigo a esposa do personagem Monsieur Lenormand de Mezy. Certa tarde, um escravo alcaguetou o maneta Mackandal, que, investido de poderes extraordinários, seria o Senhor do Veneno. O dedo-duro foi morto com um tiro nos intestinos e iniciou-se uma tempestade de açoites nas fazendas. "Naquela mesma tarde, mobilizaram-se todos os homens disponíveis para caçar Mackandal." (CARPENTIER, 2009, p. 33)

As buscas foram inúteis, não tendo sido encontrado sequer rastro do feiticeiro. $\mathrm{O}$ veneno, por outro lado, uma vez conhecida sua procedência, deteve a sua marcha. Agora que a morte havia recobrado seu ritmo normal, aos poucos a vida também voltava à normalidade. As batidas contra Mackandal iam rareando. Enquanto isso, o mito e as histórias do feiticeiro iam prosperando entre os escravos, espalhando-se relatos de seus poderes licantrópicos: uma iguana verde que aquecera o dorso no teto do secador de tabaco; uma mariposa noturna voando à luz do dia; um grande cão que roubou um pernil de veado; um alcatraz que se sacudiu sobre a parreira do quintal todos eles eram nada mais que metamorfoses de Mackandal, seus disfarces enquanto continuava a visitar as fazendas para vigiar seus fiéis e saber se ainda confiavam em sua volta. Um dia, dizia-se, ele daria o sinal do grande levante e, segundo o personagem Ti Noel, escravo de Monsieur Lenormand de Mezy, o sangue dos brancos correria até o riacho. E assim se passaram quatro anos de espera.

Finalmente capturado, preparou-se para Mackandal uma punição que deveria servir de exemplo aos demais negros. Os escravos foram levados por seus senhores, em grandes grupos escoltados por capatazes a cavalo e guardas com armamento de campanha, até a praça central da Cidade do Cabo. Nesse ínterim, os soldados amontoavam lenha ao pé de um poste. Autoridades e funcionários públicos instalavamse em altas poltronas à sombra de um toldo e nos balcões as damas com seus leques e sombrinhas se postavam para o acontecimento. Cada vez mais apertados e suarentos, os negros aguardavam o espetáculo organizado especialmente para eles. Mackandal era 
conduzido para o centro da praça, coberto de cordas e ferimentos recentes. Apesar da expectativa dos amos, os escravos demonstravam uma revoltante indiferença. Para eles os brancos nada entendiam de coisas dos negros; Mackandal, que havia passado por um ciclo de transformações, superando a ausência de um braço com a posse de várias patas, haveria de transformar-se a qualquer momento em um mosquito zombador, fugindo de seus captores.

Com o gesto do governador tacou-se fogo à pilha de lenhas que estava a seus pés. Mackandal agitou o coto e vociferou conjuros desconhecidos. Suas amarras se soltaram e seu corpo se precipitou sobre os negros, que o saudaram com um grito de "Mackandal sauvé!”. Os guardas se lançaram a coronhadas contra a turba em meio à gritaria, e poucos viram que Mackandal fora por fim jogado de cabeça no fogo, que afogou seu último grito. Quando o espetáculo terminou e os negros se acalmaram, estes voltaram a suas fazendas rindo por todo o caminho. "Mackandal cumprira sua promessa, permanecendo no reino deste mundo." (CARPENTIER, 2009, p. 45) Para eles, os brancos tinham sido ludibriados por Mackandal, que se teria metamorfoseado, enquanto para os brancos tudo isso apenas atestava a insensibilidade dos negros ante o suplício de um semelhante.

No "mundo real", por assim dizer, Mackandal foi capturado e queimado vivo na praça pública da Cidade do Cabo (Cap-Français, hoje Cap-Haïtien), no ano de 1758.

No próximo item será abordada a segunda parte da obra, que compreende o período de 1791 e 1802, com um "epílogo" em 1825.

\section{DE BOUCKMAN A BONAPARTE}

A segunda parte da obra tem como pano de fundo os estertores do período colonial, quando o domínio francês sobre o Haiti começa a se esfacelar. Os personagens históricos que protagonizam essa parte são Bouckman e Pauline Bonaparte, esta nomeada no livro como Paulina. Nessa parte há também, no capítulo 1, uma prematura menção a Henri Christophe, que viria a se tornar rei do Haiti, mas que à época dos fatos narrados era mestre-cuca e dono de um albergue na Cidade do Cabo. 
O capítulo 2 faz uma colorida recriação da Cerimônia de Bois Caïman, conduzida no dia 14 de agosto de 1791 pelo sacerdote vodu Dutty Bouckman ${ }^{5}$ (?-1791) em conjunto com uma aliança secreta de escravos. Essa cerimônia marca o início da Revolução Haitiana, que redundaria na independência do país em 1804. Bouckman é retratado por Carpentier como alguém dotado de poderosa retórica e personalidade magnética, a quem todos os presentes juraram fidelidade. Mencionam-se também seus comandantes Jean François, Biassou e Jeannot (CARPENTIER, 2009, p. 55), líderes que segundo ele libertariam os escravos de Saint-Domingue.

A revolta de Bouckman é retratada de maneira mais comedida, se comparada ao nível de detalhamentos no relato da revolta de Mackandal. A narração limita-se ao microcosmo da fazenda de Monsieur Lenormand de Mezy e a menções a posteriori. Lenormand de Mezy, surpreendido pelo início do levante, escondeu-se por dois dias no fundo de um poço seco. Enquanto isso, os negros mataram sua esposa e o contador da fazenda, saquearam a casa, incendiaram os canis e o paiol e saíram aos gritos de "morra!" aos amos, ao governador e a todos os franceses do mundo. Retornando temeroso à própria casa, após vários dias veio a saber, por um mensageiro a cavalo, que a revolta fora abafada e que a cabeça do líder, Boukman, já criava vermes no exato lugar em que Mackandal fora queimado anos antes. Encontrando-se com o governador, que tremia de nervosismo e insônia, soube dele que se planejava o extermínio total e absoluto dos escravos, assim como dos negros e mulatos livres. A colônia ia à ruína, os negros tinham violado quase todas as moças distintas da planície. Foi nesse momento que pela primeira vez prestou atenção a uma palavra que até então lhe passara despercebida: Vaudoux (vodu), designação que para ele evocava as práticas selvagens dos feiticeiros das montanhas e que naquele momento se traduzia em uma religião secreta que alentava e unia os negros rebeldes. Considerando-se a morte Bouckman, é possível datar esses fatos todos de novembro de 1791.

Maria Paola Buonaparte (1780-1825), mais conhecida como Pauline Bonaparte, irmã mais nova de Napoleão Bonaparte, protagoniza os capítulos 6 e 7 da segunda parte da obra. Casada com o general francês Charles Leclerc (1772-1802), chega com a família a Saint-Domingue em 1801, cujo governo seu marido assume. No entanto, sua estada é encurtada por um surto de varíola, que vitima Leclerc em $1^{\circ}$ de outubro de

\footnotetext{
5 Considerando-se que Bouckman era originário da Jamaica, conjectura-se que seu nome seja o afrancesamento do inglês "Book Man", ou "homem do livro", um indício de que fosse muçulmano.
} 
1802. O livro retrata uma Pauline aterrorizada ante a possibilidade de a epidemia alcançá-los na ilha de Tortuga, onde se refugiara, a ponto de participar dos rituais vodus conduzidos pelo negro Solimán, antigo garçom de uma casa de banho que passara a lhe servir como seu massagista. Pauline retorna à França tão logo lhe morre o marido. Anos mais tarde, um igualmente aterrorizado Solimán, acompanhando a viúva do rei Christophe no exílio, se depararia, em Roma, no Palazzo Borghese, com uma estátua com as formas do corpo de Pauline, cujos contornos ele bem conhecia. De fato, Pauline Bonaparte morreu em Roma, aos quarenta e cinco anos de idade, no ano de 1825.

No próximo item será abordada a terceira parte da obra, que compreende o período entre o começo do século XIX e 1820, data da morte do rei.

\section{O REINADO DE HENRI CHRISTOPHE}

A terceira parte é focada no rei Henri Christophe e na construção da Cidadela La Ferrière. Também menciona, en passant, Jean-Jacques Dessalines (1758-1806) (CARPENTIER, 2009, p. 84), ex-escravo líder da Revolução Haitiana que proclamou a independência do Haiti em 1804. Tornou-se o primeiro governante do país e, mais tarde, seguindo os passos de Napoleão, proclamou-se imperador. Morreu traído por seus colaboradores Alexandre Pétion e Henri Christophe (PRADO, 1994. p. 15.).

Henri Christophe (1767-1820), ex-escravo, militar de carreira, tornou-se presidente do Haiti em 1807 e proclamou-se rei em 1820, mesmo ano em que cometeu suicídio. ${ }^{6}$ É retratado, em El reino de este mundo, como um autocrata impopular e cruel. Sans-Souci, sua “capital”, é vista pelo personagem Ti Noel como um lugar repleto de palácios, com uma fortaleza de janelas arqueadas, terraços, estátuas, jardins, pérgulas, riachos artificiais, militares vestidos de branco, jovens capitães, palácios, damas coroadas de plumas, igrejas adornadas. Mas o que mais o assombrava era a descoberta de que esse mundo prodigioso era um mundo de negros.

O velho Ti Noel é preso e levado com outros detentos para um campo de construção. Sua função era, junto com inúmeros meninos, grávidas, mulheres e velhos, carregar um tijolo por vez até o alto de uma montanha. Trata-se aqui da construção da gigantesca Citadelle Laferrière, que durou de 1805 a 1820, localizada no alto de uma

\footnotetext{
${ }^{6}$ Enciclopédia Mirador Internacional, 1976, v. 11, p. 5640.
} 
montanha ("Gorro del Obispo", segundo o livro) no norte do Haiti. Trata-se, hoje, da maior fortaleza de todo o continente americano. Segundo El reino de este mundo, negros morriam diariamente na obra, mas ninguém dava por sua falta. Centenas de homens trabalhavam na imensa construção, sempre vigiados. A obra seguia noite adentro e toda a população do norte fora mobilizada para ali trabalhar. Ninguém mais ousava reclamar, em face da repressão do regime. Ti Noel considerava que o pior de tudo era ser espancado por outro negro; noutros tempos os colonos pelo menos evitavam matar seus escravos, já que eram parte de seu patrimônio; já ali a morte de um negro nada custava ao tesouro público. O rei Christophe sempre subia à Cidadela postada próximo ao céu.

O saque ao Palácio de Sans-Souci, residência do rei Christophe, merece especial atenção de Carpentier. O rei testemunhou a debandada geral de sua corte e de seus soldados, que num grande motim abandonavam o palácio. A rainha e as princesas choravam. O rei se pôs a andar pelo palácio vazio, refletindo sobre como procurara dar à sua corte uma aparência europeia, fugindo à mística africanista dos primeiros caudilhos. Nesse momento a noite se encheu de tambores, com chamados de montanha a montanha, subindo das praias e das cavernas, retumbando tambores que invocavam Bouckman. Começava a invasão de seu palácio pelo povo, que a tudo incendiava e destruía em seu caminho. O rei se matou com uma arma antes que os revoltosos o alcançassem. O corpo do rei foi carregado pelos últimos serviçais fiéis, acompanhado da rainha e das princesas, que fugiam em disparada no meio da noite rumo à Cidadela La Ferrière. Ao longe o palácio real ardia em chamas, com tudo o mais tomado e saqueado pelo povo revoltoso. Quase ao amanhecer chegaram à Cidadela, onde sepultaram o corpo do rei em meio a uma argamassa fresca. O exército real debandou de vez. O governador da fortaleza cortou um dos dedos mínimos do rei, entregando-o à rainha, que o guardou. $\mathrm{O}$ corpo do rei se misturava à própria matéria da fortaleza.

Os fatos acima descritos são datáveis de outubro de 1820, cujo ápice se dá com o suicídio de Henri I, com uma bala de prata, no oitavo dia desse mês. ${ }^{7}$ No próximo item será abordada a quarta e última parte da obra, que retrata o início da experiência republicana no Haiti, em algum momento do segundo quarto do século XIX, entre a morte de Pauline Bonaparte em 1825 e a morte de Boyer em 1850.

\footnotetext{
${ }^{7}$ Enciclopédia Mirador Internacional, 1976, v. 11, p. 5640.
} 


\section{A REPÚBLICA}

A quarta e última parte se passa já durante a República Haitiana. O presidente Jean-Pierre Boyer (1776-1850), segundo presidente do país e responsável por sua reunificação, é mencionado brevemente: para acalmar Solimán, que se aterrorizara ao encontrar no Palácio Borghese uma estátua com as formas de Pauline Bonaparte (a Venus Victrix, do escultor italiano Antonio Canova), a ex-rainha María Luisa (MarieLouise Coidavid) recorre aos chás de ervas amargas que recebia, via Londres, do presidente Boyer (CARPENTIER, 2009, p. 120).

Em especial essa parte demonstra uma tentativa de racionalização do governo e da administração pública, embora por meio de iniciativas danosas à população pobre. Ti Noel uma manhã recebeu a inesperada visita de agrimensores, que mediam suas terras e o ignoravam enquanto falavam o idioma dos franceses. Ti Noel exigiu que se retirassem, mas fizeram-lhe pouco caso. Humilhado, escondeu-se numa chaminé, de onde gritava imprecações. Depois percebeu que os agrimensores estavam por toda parte e que muitos camponeses abandonavam suas choças. Os mulatos eram para ele uma novidade.

Mackandal não tinha previsto isso de trabalho obrigatório. Tampouco
Buckman, o Jamaicano. Os mulatos eram uma novidade em que não
poderia ter pensado José Antonio Aponte, ${ }^{8}$ decapitado pelo marquês
de Someruelos, cuja história de rebeldia era conhecida por Ti Noel
desde seus dias de escravidão cubana. Por certo nem sequer Henri
Christophe teria suspeitado que as terras de São Domingos iriam
propiciar essa aristocracia confusa e perplexa, essa casta quarterã, que
agora se apoderava das antigas fazendas, dos privilégios e das
investiduras. (CARPENTIER, 2009, p. 126)

Invocando lembranças de Mackandal e Bouckman, Ti Noel percebeu quão fácil era transformar-se em animal, metamorfoseando-se em ave, garanhão, vespa, formiga.

Ti Noel recebeu em sua propriedade gansos dos antigos viveiros do palácio real, salvos do saque porque sua carne não agradava os negros. O bando se organizava de acordo com os antigos conselhos africanos e o velho tentou unir-se a ele, mas não foi

\footnotetext{
${ }^{8}$ Líder de uma revolta de escravos em Cuba no ano de 1812.
} 
aceito. Compreendeu que o repúdio dos gansos era um castigo por sua covardia. "Mackandal disfarçara-se de animal, durante anos, para servir aos homens, e não para desertar do terreno dos homens." (CARPENTIER, 2009, p. 130) O homem só pode encontrar sua grandeza no Reino deste Mundo, concluiu. Subindo numa mesa que tomara no saque ao Palácio de Sans-Souci, “[o] velho lançou sua declaração de guerra aos novos senhores, dando ordem a seus súditos de tomar de assalto as obras insolentes dos mulatos investidos de autoridade" (CARPENTIER, 2009, p. 131).

Veio então uma feroz tempestade e desde esse momento ninguém mais soube de Ti Noel, salvo talvez um certo abutre molhado. Esse final dúbio indica a possível metamorfose de Ti Noel ou, por outro lado, anuncia sua morte.

\section{CONSIDERAÇÕES FINAIS}

Alejo Carpentier emprega, na composição de El reino de este mundo, diversos elementos reais e históricos de profundo significado no contexto da Revolução Haitiana, apresentando-os ora no centro da cena, ora como pano de fundo da narrativa. Embora não datados nem nomeados, os fatos são claramente identificáveis, assim como os personagens reais e os lugares concretos mencionados ao longo da obra. O próprio autor admite esse artifício no Prólogo do livro, apontando para o rigor empregado em sua pesquisa e no cotejo de datas e nomes.

Estão retratados no enredo acontecimentos históricos como: (I) a revolta de Mackandal, na década de 1750, quando escravos sublevados, liderados por um chefe vodu de origem africana, envenenaram sorrateiramente, com poções de plantas, os colonos franceses da colônia de Santo Domingo; (II) a Cerimônia de Bois Caïman (14 de agosto de 1791) e a revolta de Bouckman (encerrada em novembro de 1791), ocasião em que os negros se insurgiram maciçamente contra os franceses, destruindo fazendas e matando colonos; (III) a expedição de Santo Domingo, capitaneada pelo general Charles Leclerc, que visava restaurar a ordem e o poder da França na colônia convulsionada (1801-1803); (IV) a construção da Cidadela La Ferrière (1805-1820), a maior fortaleza do continente; (V) o saque ao palácio de Sans-Souci pelo povo e o suicídio do rei Henri Christophe (1820). 
Pessoas reais que tiveram envolvimento destacado nos acontecimentos aparecem, ficcionalizadas, como personagens centrais em determinadas passagens da narrativa, tais como Mackandal (?-1758), escravo e sacerdote vodu ("Houngan") que liderou uma revolta de escravos que acabaria por envenenar inúmeros colonos franceses na colônia de Santo Domingo, tendo sido afinal preso e queimado vivo em praça pública, numa das cenas mais dramáticas e intensas do livro (Mackandal aparece na parte I, capítulos 1 a 8); Dutty Bouckman (?-1791), escravo oriundo da Jamaica e feiticeiro vodu responsável por conduzir a famosa Cerimônia de Bois Caïman e por liderar a revolta de escravos de 1791, tendo sido afinal decapitado, cujo nome evoca o afrancesamento de "Book Man", ou "Homem do Livro", o que permite deduzir sua suposta origem muçulmana (parte II, capítulos 1 a 3); Paulina ou Pauline Bonaparte, nascida Maria Paola Buonaparte (17801825), irmã de Napoleão Bonaparte e esposa do general Leclerc, que viveu com a família em Santo Domingo entre 1801 e 1802 (parte II, capítulos 6 e 7); Henri Christophe (1767-1820), ex-escravo, mestre-cuca e militar que se tornou presidente do Haiti em 1807 e se proclamou rei em 1820 (parte II, capítulo 1, e parte III, capítulos 1 a 7).

Também figuram personagens reais secundários, que não têm a personalidade nem quaisquer subjetividades aprofundadas pelo autor, embora com participações pontuais destacadas: Jean-François, Biassou e Jeannot, escravos revoltosos nomeados seus comandantes por Bouckman durante a Cerimônia de Bois Caïman (1791); o general Charles Leclerc (1772-1802), cunhado de Napoleão Bonaparte, responsável por restabelecer a ordem e a autoridade da França na colônia, comandando a expedição de Santo Domingo; a rainha María Luiza (Marie-Louise Christophe, nascida Marie-Louise Coidavid, 1778-1851), esposa de Henri Christophe, e as princesas Françoise-Améthyste e Athénaïs, que embora não nomeadas no livro estão presentes em passagens marcantes, como o saque de Sans-Souci, o enterro do rei e o período italiano da rainha.

Há ainda personagens reais citados apenas nominalmente, sem participação ativa na trama: Jean-Jacques Dessalines (1758-1806), ex-escravo herói da independência do Haiti autoproclamado imperador (CARPENTIER, 2009, p. 84); o capuchinho Cornejo Breille, também referido como Corneille Brelle ou Jean-Baptiste-Joseph Brelle (17541819), emparedado no edifício do Arcebispado por ordem do rei para evitar que retornasse à França com todos os seus segredos (CARPENTIER, 2009, p. 97); o 
presidente Jean-Pierre Boyer (1776-1850), responsável por reunificar o país após Henri Christophe (CARPENTIER, 2009, p. 120); José Antonio Aponte, líder de uma revolta de escravos em Cuba entre 1811 e 1812 (CARPENTIER, 2009, p. 126).

Por fim, figuram personagens que, por sua verossimilhança, aparentam ser inspirados em pessoas reais, ainda que, é lícito supor, tenham tomado tão-somente o nome de empréstimo a pessoas que existiram de verdade. É o caso, por exemplo, do negro Solimán, antigo garçom de uma casa de banho que, na história de Carpentier, passou a massagista de Pauline Bonaparte e mais tarde, como cortesão, carregou o corpo de Henri Christophe e participou de seu enterro, afinal acompanhando a rainha em seu exílio italiano. Não nos foi possível apurar se o personagem Solimán foi de fato inspirado em alguma pessoa real.

Já personagens como Ti Noel, Monsieur Lenormand de Mezy e sua esposa Floridor são claramente fictícios. Ti Noel, aliás, é o personagem principal de toda a história, fazendo-se presente, participando ou testemunhando a distância os principais acontecimentos históricos apropriados pela narrativa.

Dentre os lugares reais que servem de palco para os acontecimentos, entre a segunda metade do século XVIII e as primeiras décadas do XIX, destacam-se: (I) Santo Domingo, ou Saint-Domingue, colônia francesa de 1627 a 1804, na parte ocidental da Ilha de Hispaniola, que daria origem ao Haiti quando de sua independência; (II) a Cidade do Cabo, ou Cap-Français, hoje Cap-Haïtien, onde o personagem Ti Noel passa boa parte da vida e que visita uma última vez na velhice; (III) o albergue La Corona, na rua dos Espanhóis, Cidade do Cabo, cujo cozinheiro havia sido ninguém menos que Henri Christophe; (IV) Santiago de Cuba, destino de muitos antigos colonos franceses que migraram após os prejuízos e perdas humanas devidos à revolta liderada por Bouckman; (V) a ilha de Tortuga, ou Île de la Tortue, onde Pauline Bonaparte se refugiou da epidemia de tuberculose e onde Leclerc viria a morrer; (VI) Sans-Souci, a capital de Henri Christophe, e o Palácio de Sans-Souci, residência do rei saqueada pelo povo insurreto em 1820; (VII) a Cidadela La Ferrière, ou Citadelle Laferrière, imensa fortaleza construída no alto de um morro no norte do Haiti à custa de enormes esforços e vidas humanas, que acabou servindo de mausoléu para o corpo de Henri Christophe; (VIII) Roma, onde viveram a ex-rainha María Luíza e suas filhas; (IX) o Palácio Borghese, em Roma, onde se encontra uma estátua em mármore, a Venus Victrix, 
concluída em 1808, esculpida pelo escultor italiano Antonio Canova a partir das formas de Pauline Bonaparte (à época já Pauline Borghese), esta considerada uma das mulheres mais belas de seu tempo.

Como se vê, a ficcionalização do passado histórico é um dos principais recursos empregados por Carpentier na composição de El reino de este mundo, que o faz com maestria. O resultado é uma obra de ficção, um "romance histórico", com méritos à altura das grandes obras do gênero e com densidade à altura de retratar um dos marcos fundadores da América Latina, a Independência do Haiti em 1804, primeiro país da região a se libertar da opressão colonial. Nesse sentido, o crítico estadunidense Seymour Menton (apud WEINHARDT, 2011, p. 45) assinala El reino de este mundo como a obra inaugural do subgênero literário ao qual denomina "a nova novela histórica da América Latina", referindo-se a ela pela sigla NNH. Além disso, a obra introduz o Real Maravilhoso na literatura latino-americana do século XX, tema complexo e instigante que também tematiza o intersecção entre o real e o fictício, do qual convém tratar em outra oportunidade.

Se Carpentier empreendeu uma "ficcionalização do passado histórico" no enredo de sua obra, o presente artigo buscou desvendar a "historicidade presente na ficção", que lhe terá servido de referência, ao separar o "mundo" do "reino", ou o mundo real do reino da ficção, cujo entrecruzamento constitui o principal recurso narrativo de Carpentier em El reino de este mundo.

\section{REFERÊNCIAS}

BOSI, Alfredo. O ser e o tempo da poesia. São Paulo: Cia das Letras, 2000.

CANDIDO, Antônio. Literatura e sociedade. São Paulo: Nacional, 1967.

CARPENTIER, Alejo. O reino deste mundo. Tradução de Marcelo Tápia. São Paulo: Martins Fontes, 2009.

ENCICLOPÉDIA MIRADOR INTERNACIONAL. São Paulo / Rio de Janeiro: Encyclopaedia Britannica do Brasil Publicações, 1976.

PRADO, Maria Ligia. A formação das nações latino-americanas. São Paulo: Atual, 1994. 
Fábio A. Vargas

WEINHARDT, Marilene. Romance histórico: das origens escocesas ao Brasil finissecular. In: WEINHARDT, Marilene (Org.). Ficção histórica: teoria e crítica. Ponta Grossa: Editora UEPG, 2011.

Recebido em 08/10/2017.

Aceito em 02/04/2018.

Publicado em 02/04/2018. 